\title{
New technologies and information overload
}

The Machine is much, but it is not everything. - E.M. Forster, "The Machine Stops," 1909

A ccess to medical information is apparently unprecedented. Yet for older doctors like myself this information is made inaccessible through an impenetrable barrier of technology and a barrage of irrelevance. So if you have been having difficulties similar to mine, I have a lowcost, low-tech, user-friendly solution to recommend.

Recently I was treating a patient with disabling angina who needed coronary angiography. Unfortunately, she suffered from intractable restless leg syndrome, making the requisite four hours of immobility a difficult obstacle. A third-year medical student who was with me at the time reassured me that his personal digital assistant (PDA) would provide the answer. Yet a frantic search through the five textbooks stored on his device yielded nothing. Technology failed us.

Information technology has frustrated me before. I regularly open up patients' coronary arteries with a variety of gizmos and devices. After this, postprocedure orders are entered into the hospital system by our fellows. If this is not done, the patient cannot leave the catheterization laboratory. On one occasion a crisis occurred. The fellows were unavailable, and so I did my cases solo. Unfortunately, when I tried to enter the orders I discovered that the screens had changed in the 2 months since I had last used them. I was stymied. It looked like the patient and I were going to spend the night in the catheterization suite. Thankfully, I was rescued by one of our trainees wandering through the lab. Although I try to embrace change, it is sometimes an unwilling partner.

I want to keep up. Not only does it make my work more interesting and fun, but it's also my responsibility as a doctor. Even a subspecialist needs to be a good generalist. I wish PDAs helped me keep up-to-date, but they do not. I learn by repetition, engagement, individualization and writing. PDAs require none of these.

According to Francis Bacon, "Reading maketh a full man; conference a ready man; and writing an exact man. And therefore, if a man write little, he had need have a great memory." My memory has its limitations, and so do my eyesight and dexterity. But even my younger colleagues have difficulty with their PDAs' small screens and tiny stylets. What chance do I have of gaining control over such a device?

So how, from a flood of information, does one extract timely answers to clinical questions? I subscribe to seven journals; this translates into about 300 new papers monthly. It is a challenge not only intellectually but also physically to keep up.

I am a cutter and saver. I still have notes from grand rounds during my internship at Philadelphia General Hospital in 1964 , and for over forty years I have cut articles out of journals and filed them at home. My file cabinet now runneth over, not to mention the accumulation of dormant research files in the crawl space in my house. My wife read me the riot act: Do something about your "stuff" or it all goes out. The shredding truck was summoned; it disposed of ten years of research files in as many minutes. But I could not permit the shredding of years of precious journals and notes.

As fate would have it, a solution appeared in the unlikely circumstance of a hip replacement. For the first time in my working life I was sequestered at home, relatively immobile. Too restless for afternoon siestas and bored by Oprah and Dr. Phil, I needed something more. I decided that this was the time to revise how I was handling information overload. Previously, as I reviewed my monthly stack of journals, those articles of any relevance to me were cut out, kept, read and even dis-

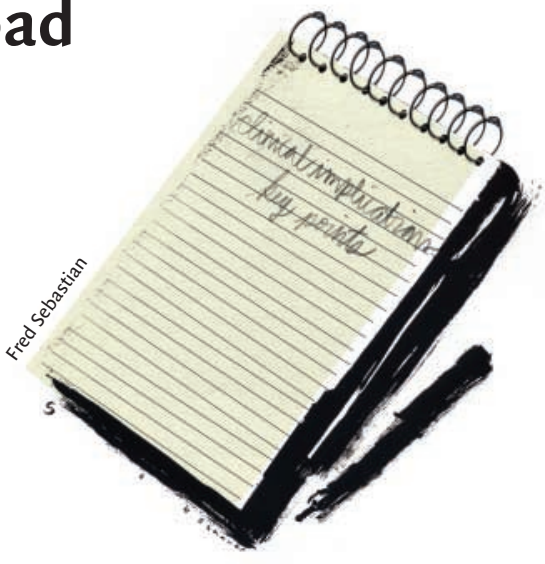

cussed, but by the next day I had little recollection of details. By Bacon's standard, I may have been a full man and even a ready man but I was not an exact man. I was browsing.

Almost all papers have a "bottom line" that can be summarized in one or two sentences, even more briefly than in the abstract. I no longer save any journals, new or old, aside from truly seminal articles. Instead I summarize them into a booklet that I carry with me for reading on the subway or for a quick search.

Of course, there are disadvantages to this approach. It is labour intensive, and the various topics are arranged helter-skelter, but my notebook is still portable, does not require booting up, is never "down" and the writing is large enough to read. Refinements will be necessary, but it seems to be working for me. I am more engaged when I read journals or attend rounds, searching for the "bottom line." I am becoming better educated and more empowered. Granted, my solution is not for everyone. I suspect my younger colleagues will consider it rather simplistic and archaic. However, for those a bit longer in the tooth it may represent an alternative to surrendering to information overload. I realize there is too much to know, but why not know a little bit well?

\section{Leonard Schwartz}

University Health Network

University of Toronto

Toronto, Ont. 